\title{
ARE TRAUMATOLOGISTS TREATING OSTEOPOROSIS TO PREVENT NEW FRACTURES IN BRAZIL?
}

\section{OS TRAUMATOLOGISTAS TRATAM OSTEOPOROSE, PARA PREVENIR UMA NOVA FRATURA, NO BRASIL?}

\author{
Calo Zamboni ${ }^{1}$, Marina Sousa $C_{a r v a l h o}{ }^{1}$, Eduardo Araujo Pires $^{1}$, Jorge Rafael Durigan ${ }^{1}$, Patricia Maria de Moraes Barros Fucs ${ }^{1}$, \\ MARCELO TOMANIK MERCADANTE ${ }^{1}$
}

1. Department of Orthopedics and Traumatology, Santa Casa de São Paulo, SP, Brazil.

\section{ABSTRACT}

Objectives: To determine the proportion of traumatologists who investigate osteoporosis in elderly patients with fractures and recommend secondary prevention of osteoporotic fractures. Methods: We distributed questionnaires to 244 physicians attending the 2015 Brazilian Congress of Orthopedic Trauma. We determined the respondents' profiles and assessed how they investigated and treated osteoporosis in elderly patients with fractures. Results: Overall, $32 \%$ of the respondents reported that their knowledge level regarding osteoporosis ranged from 0-5 (out of $0-10$ ). In total, $42 \%$ of the participants reported that they usually requested DXA for elderly patients with fractures and less than $30 \%$ reported prescribing supplemental calcium and/or vitamin $\mathrm{D}$. We considered physicians conducting a complete treatment for the patient as those who in addition to requesting DXA prescribed supplemental calcium, vitamin $D$, and specific medications for their elderly patients, and recommended non-pharmacological measures. Only $0.8 \%$ of the participants fulfilled all these criteria. In addition, $47 \%$ of the traumatologists reported that they did not treat osteoporosis directly but instead, referred osteoporotic patients to a qualified physician. Conclusion: Less than $50 \%$ of the surveyed traumatologists investigated and performed secondary prevention against osteoporotic fractures after treating an elderly patient with a fracture. Level of evidence III, Economic and Decision Analyses - Developing an Economic or Decisions Model.

Keywords: Osteoporosis. Osteoporotic Fracture. Secondary Prevention. Surveys and Questionnaires.

\section{RESUMO}

Objetivo: Avaliar a proporção de traumatologistas que investigam a osteoporose nos pacientes idosos com fraturas e recomendam a prevenção secundária das fraturas osteoporóticas. Métodos: Distribuímos questionários para 244 médicos participantes do Congresso Brasileiro de Traumatologia Ortopédica em 2015. Determinamos o perfil dos mesmos e avaliamos como os entrevistados investigam e tratam a osteoporose nos pacientes idosos com fraturas. Resultados: Entre os entrevistados, 32\% relataram que seu nivel de conhecimento sobre osteoporose seria algo entre 0 e 5 (de 0 a 10). No total, $42 \%$ dos participantes relataram que frequentemente solicitam DXA para pacientes idosos com fraturas, mas menos de $30 \%$ relataram prescrever suplementação com cálcio e/ou vitamina $D$. Consideramos como prescritores do tratamento completo para o paciente aqueles médicos que, além de solicitar DXA, prescrevem suplementação de cálcio, vitamina $D$ e medicamentos específicos para seus pacientes idosos, além de recomendar medidas não farmacológicas. Apenas $0,8 \%$ dos participantes preencheram todos esses critérios. Além disso, $47 \%$ dos traumatologistas relataram que não tratam a osteoporose, mas encaminham seus pacientes com osteoporose para um médico que o faz. Conclusão: Menos de 50\% dos traumatologistas pesquisados investigam e realizam prevenção secundária contra fraturas osteoporóticas após tratamento de paciente idoso com fratura. Nível de evidência III, Análises econômicas e de decisão - Desenvolvimento de modelo econômico ou de decisão.

Descritores: Osteoporose. Fraturas por Osteoporose. Prevenção Secundária. Inquéritos e questionários.

Citation: Zamboni C, Carvalho MS, Pires EA, Durigan JR, Fucs PMMB, Mercadante MT. Four-level en bloc vertebrectomy: A novel technique and literature review. Acta Ortop Bras. [online]. 2018;26(6):384-7. Available from URL: http://www.scielo.br/aob.

\section{INTRODUCTION}

Osteoporosis is characterized by decreased bone mineral density and disruption of the bone microarchitecture leading to increased bone fragility. ${ }^{1}$ It is defined by the World Health Organization as a bone mineral density T-score below -2.5 standard deviations determined by dual-energy $x$-ray absorptiometry (DXA). ${ }^{2}$ According to current estimates, osteopenia and osteoporosis affect millions of individuals worldwide. ${ }^{2-5}$ Osteoporosis, which often affects elderly

All authors declare no potential conflict of interest related to this article.

Work conducted at the Department of Orthopedics and Traumatology of Santa Casa de Sao Paulo School of Medical Sciences, São Paulo, SP, Brazil. Correspondence: Caio Zamboni. Rua Dr. Cesário Mota Junior, 112, São Paulo, SP, Brazil. 01221-020. contato@drzamboni.com.br 
patients, may be a silent disease until complicated by a fracture, which may occur with minimal trauma or even in its absence. Fractures of the vertebra, proximal femur, and distal radius are considered sentinel events. ${ }^{5}$ Up to $50 \%$ of women and $20 \%$ of men older than 50 years are estimated to have an osteoporotic fracture throughout life. ${ }^{3}$

In this context, it is important to consider the costs associated with hospital admissions, outpatient care, and medical procedures to treat these fractures, which are potentially preventable in a large proportion of patients. ${ }^{5-8}$

We must understand the importance of properly treating osteoporosis to prevent serious complications such as new fractures and secondary deformities, chronic pain, and loss of independence. These measures may also reduce mortality in the elderly population. Still, we observe that the diagnosis and treatment of this disease are flawed in many countries worldwide.1,4,9

The aim of this study was to assess the percentage of orthopedic traumatologists in Brazil who investigate and treat osteoporosis with the objective of preventing new fractures in elderly patients.

\section{MATERIALS AND METHODS}

We invited participants of the $21^{\text {st }}$ Brazilian Congress of Orthopedic Trauma (Congresso Brasileiro de Trauma Ortopédico, CBTO), held in May 2015 in Belém (Pará, Brazil), to fill out an anonymous questionnaire. The questionnaire consisted of multiple-choice questions and was answered by 244 physicians, of whom 184 were orthopedic traumatologists and 60 were residents in orthopedics and traumatology. The data obtained were analyzed and correlated using the programs Excel 2011 and Epilnfo, version 3.5.2.

The research project of this study was approved by the Ethics Committee in Research (CAAE 39276614.5.0000.5479). The physicians who filled out the questionnaires signed a Free and Informed Consent Form. We determined the profile of the participating physicians by including two questions in the survey: (1) For how long (in years) have you been practicing orthopedics? and (2) In which region of Brazil do you practice? The answers to these questions were compared with deidentified data from the Brazilian Society of Orthopedic Trauma (Sociedade Brasileira de Trauma Ortopédico, SBTO) in order to evaluate how the participants would compare with the actual profile of the overall sample of orthopedic traumatologists in Brazil.

We assessed the degree of knowledge of the participants regarding osteoporosis, and whether they investigate and treat the disease, and if they do so, how they conduct the investigation and treatment. We also questioned the degree of knowledge that the surveyed traumatologists consider to have regarding the disease, and how much they wish they knew about it. In order to assess the knowledge about the disease, we asked the participants to select among six options the correct T-score cutoff value that establishes the diagnosis of osteoporosis, as defined by the World Health Organization. ${ }^{2}$ To evaluate if the participants performed any investigation or treated osteoporosis, we asked them if after diagnosing and treating a fracture in an elderly patient, whether they request any additional tests to identify or confirm the occurrence of osteoporosis. We also asked if they recommend non-pharmacological measures and prescribe supplemental calcium, vitamin D, or any specific medication (antiresorptive agents or bone forming agents) to at least $50 \%$ of their patients.

For the purpose of this research, we considered as managing osteoporosis adequately those physicians who:

- Requested DXA to investigate or confirm a diagnosis of osteoporosis;

- Answered the correct T-score value that establishes the diagnosis of osteoporosis (-2.5 standard deviations);
- Prescribed supplemental calcium and vitamin D to at least $50 \%$ of their elderly patients diagnosed with a fracture;

- Prescribed any medication specifically to treat osteoporosis to at least $50 \%$ of their elderly patients diagnosed with the disease;

- Recommended some type of non-pharmacological treatment/ prevention (such as fall prevention, smoking cessation, decrease in alcohol consumption, or regular physical activity);

- Referred the patient to a specialist qualified to treat osteoporosis (for those participants who did not treat osteoporosis).

\section{RESULTS}

Table 1 shows the distribution of the participants according to the region in Brazil where they practice orthopedics. Excluding the residents who answered the questionnaire, $40 \%$ of the participants reported to have been practicing orthopedics for less than 10 years, whereas the remaining 60\% reported more than 10 years of practice. Data obtained from the SBTO showed that $27 \%$ of the members of the society had concluded training less than 10 years before the data were collected, whereas $73 \%$ had done so more than 10 years before.

When questioned about their degree of knowledge about osteoporosis on a scale between 0 (zero) and 10 (ten), 32\% of the participants responded knowing between $0-5$, and 68\% reported knowing between $6-10$. A total of $97.5 \%$ of those who reported knowing between $0-5$ answered that they would like their degree of knowledge about osteoporosis to increase to 6-10.

When we asked if the physicians would be interested in participating in a workshop/seminar if promoted by the SBTO, Brazilian Society of Orthopedics and Traumatology (Sociedade Brasileira de Ortopedia e Traumatologia, SBOT), or some other medical society or recognized educational institution, $91 \%$ responded that they would. When we assessed the degree of knowledge of the participants about osteoporosis, $76.5 \%$ of the residents and $66 \%$ of the traumatologists answered the correct T-score cutoff value. A total of $42 \%$ of the participants responded that they request DXA to investigate or diagnose osteoporosis in an elderly patient with a fracture, but when we analyzed only the responses given by residents, the corresponding rate was much lower (16\%). Among the physicians who reported requesting DXA, 35\% answered incorrectly the T-score cutoff value that determines the diagnosis of osteoporosis.

When we excluded the responses by residents, we found that $18 \%$ of the respondents prescribe vitamin D, 24\% prescribe calcium, and $27 \%$ prescribe antiresorptive/bone forming agents during follow-up of elderly patients diagnosed with a fracture. Among medical residents, the corresponding percentages are $3.4 \%$ for supplemental calcium and vitamin D and $1.6 \%$ for specific medications. The corresponding values are $3.4 \%$ for supplemental calcium and vitamin $\mathrm{D}$, and $1.6 \%$ for specific medications.

Table 1. Distribution of the participants according to the region in the country where they practice and compared with data provided by the Brazilian Society of Orthopedics and Traumatology (SBTO).

\begin{tabular}{c|c|c|c|c|c}
\hline Region & Total $\mathbf{n}$ & $\%$ & ER $\mathbf{n}$ & $\%$ & SBTO \\
\hline North & 27 & $11.06 \%$ & 22 & $11.95 \%$ & $4.22 \%$ \\
\hline Northeast & 34 & $13.93 \%$ & 28 & $15.21 \%$ & $11.22 \%$ \\
\hline Midwest & 14 & $5.73 \%$ & 14 & $7.60 \%$ & $6.55 \%$ \\
\hline Southeast & 157 & $64.34 \%$ & 113 & $61.41 \%$ & $60.49 \%$ \\
\hline South & 12 & $4.91 \%$ & 7 & $3.80 \%$ & $17.49 \%$ \\
\hline Total & 244 & $100 \%$ & 184 & $100 \%$ & $100 \%$ \\
\hline
\end{tabular}

Total $n$ - Total number of participants; \% - Percentage; ER $n$ - All participants, excluding residents. SBTO - Percentage of members of the Brazilian Society of Orthopedic Trauma (Sociedade Brasileira de Trauma Ortopédico ) distributed by geographical region of practice. 
As for non-pharmacological treatment, $41 \%$ of the participants reported as offering this recommendation, with similar rates between traumatologists and residents (45.7\% and $38.9 \%$ respectively). Overall, $47 \%$ ( $n=103$ out of 244$)$ of the respondents reported requesting DXA, of whom $65 \%$ ( $n=67$ out of 103) knew the correct T-score value. A total of 34 respondents (52\% of 67 or $14 \%$ of 244) also prescribe supplemental calcium and vitamin D, and nine of these (26\% of 34 or $3.6 \%$ of 244 ) prescribe a medication specifically to treat osteoporosis. Only two respondents $(22 \%$ of 9 or $0.8 \%$ of 244 ) reported that they conduct a complete treatment in which they request and interpret the tests, prescribe supplemental calcium, vitamin D and appropriate medications, and recommend non-pharmacological treatment (Figure 1).

Overall, $47 \%$ of the traumatologists and $43 \%$ of the residents reported not treating osteoporosis but instead, referring their patients to a medical professional who is qualified to do so.

\section{DISCUSSION}

When we compared the profile of the participants, we observed that they share similar characteristics with members of the SBTO in terms of the region of the country where they practice. The values remained within 95\% confidence intervals for the Midwest, Southeast, and Northeast regions, but were above the interval for the Northern region and below it for the Southern region. This may be explained by the fact that the meeting was located in the Northern region of Brazil (Belém, PA) and also by the continental dimensions of our country. Still, the similarities between the groups confirm that our cohort was representative of the overall members of SBTO.

There was a greater participation of physicians who had finished training less than 10 years before the survey when compared with data provided by SBTO. In our understanding, this is due to the fact that individuals who have been practicing for less time tend to participate more frequently in workshops and meetings, seeking to improve knowledge to make up for a shorter experience, and possibly a greater academic commitment, availability, and disposition to participate in the study and fill out the questionnaire. Regarding secondary prevention, traumatologists in practice for more than 10 years have a greater commitment to research, knowledge, and treatment of osteoporosis, and are more prone to recommend secondary prevention, whereas those with a shorter practice experience refer their patients to specialized care (Figure 2).

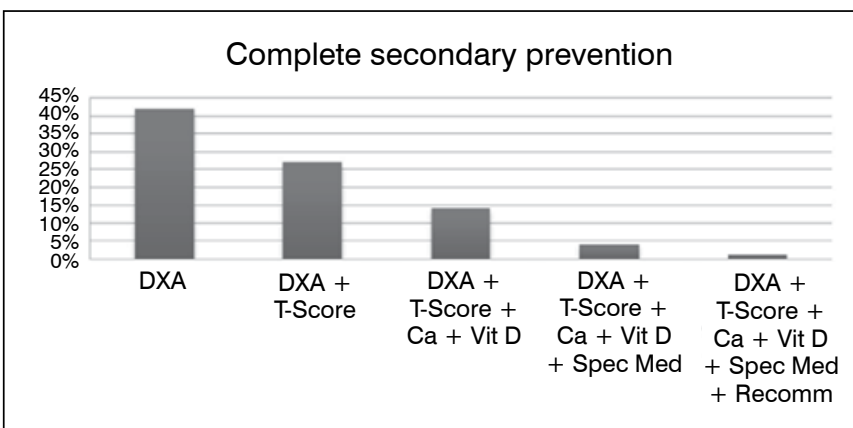

Figure 1. Percentages of physicians who conduct a complete treatment of osteoporosis. Among all participants, the percentages of those who request DXA (DXA), also knows the correct T-score cutoff value (DXA + T-score), also prescribes supplemental calcium and vitamin D (DXA + T-score $+\mathrm{Ca}+$ Vit D), also prescribes specific medications (DXA + T-score $+\mathrm{Ca}+$ Vit D + Sp Med [antiresorptive or bone forming agents]), and also recommends non-pharmacological measures to their patients (DXA + T-score + Ca + Vit D + Sp Med + Recomm).

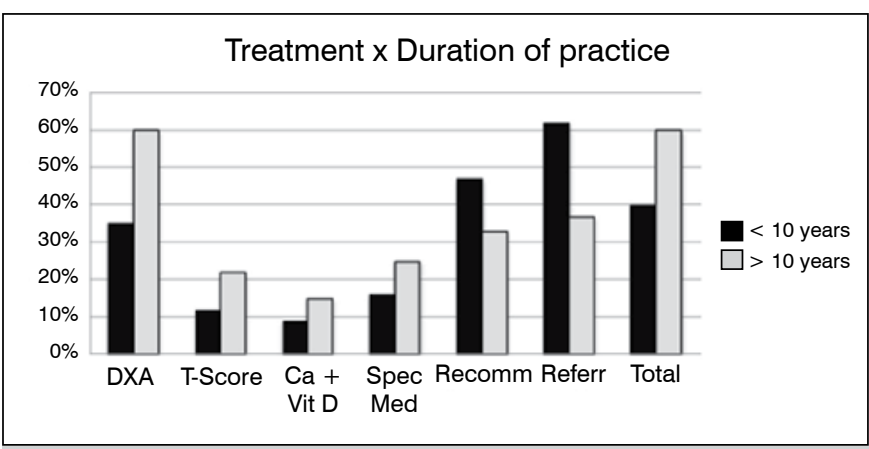

Figure 2. Distribution of follow-up scenarios according to the duration of orthopedics practice. The bars show the percentages of participants who reported requesting DXA (DXA), knowing the correct T-score to establish a diagnosis of osteoporosis (T-score); recommending supplemental calcium and vitamin $\mathrm{D}(\mathrm{Ca}+\mathrm{Vit} \mathrm{D})$, prescribing specific medications for osteoporosis (Spec Med), recommending non-pharmacological measures (Recomm), and referring the patient when not performing treatment (Referr)

The large difference observed between the numerical values obtained with the questions "How much do you think you know?" (average $=6$ ) and "How much would you like to know?" (average $=9.3$ ) suggests that the participants are interested in osteoporosis and are willing to learn about it, a fact that was confirmed when $90 \%$ answered that they would have an interest in participating in a workshop/meeting organized on this subject by a recognized medical society or institution.

When we assessed specifically the participants' technical knowledge about osteoporosis treatment, most traumatologists and residents knew the correct T-score value; however, less than half of them reported requesting additional tests to investigate the diagnosis or support the treatment, with only $16 \%$ of the residents having reported doing so. This finding is concerning because it demonstrates an inconsistency in the process of specialized medical training that needs to be corrected. The National Osteoporosis Foundation and the World Health Organization recommend that all adults older than 50 years who are diagnosed with a fracture should be investigated with DXA. 2,10

The treatment of osteoporosis involves both pharmacological and non-pharmacological measures. Medical entities such as the Brazilian Society of Endocrinology and Metabolism (Sociedade Brasileira de Endocrinologia e Metabologia) and the World Health Organization have demonstrated that the amount of calcium and vitamin D consumed by the population usually falls short of the actual requirement, and their supplementation is often necessary. 2,5,11,12 Regarding specific medications to treat osteoporosis, such as antiresorptive and bone forming agents, several studies and systematic reviews have demonstrated their efficacy in secondary prevention. ${ }^{13-16}$

We considered as appropriately recommending secondary prevention those traumatologists who reported that they investigated the occurrence of osteoporosis, knew the definition of the disease according to current and established criteria, prescribed pharmacological treatment and supplementation, and recommended non-pharmacological measures. ${ }^{17}$ Only $0.8 \%$ of the traumatologists and none of the residents fulfilled all these criteria.

We also considered as appropriately managing the patients those surgeons who after treating an osteoporotic fracture, referred the patient to a specialist qualified to treat the osteoporosis. Less than half of the traumatologists (47\%) and residents (43\%) reported doing that. This fact is concerning, considering that many fractures could be avoided if the underlying disease were treated correctly. ${ }^{5,7,13,18,19}$ Although this is a global problem, 
it has some particularities in Brazil, as reflected by a study among physicians members of the Brazilian Society of Internal Medicine (Sociedade Brasileira de Clínica Médica) that has shown that only $35 \%$ of the general practitioners believe that osteoporosis treatment is effective. ${ }^{20}$

\section{CONCLUSION}

Our results show that less than half of the traumatologists in Brazil diagnose and recommend secondary prevention for osteoporotic fractures, only $0.8 \%$ of them treat these patients correctly, and $47 \%$ refer the patients to specialized care.

AUTHORS' CONTRIBUTIONS: Each individual author contributed individually and significantly to the development of this work. CZ (0000-0001-9256-4150)*: Responsible researcher. Elaborated the study and performed the analysis of the datas; MSC $(0000-0002-4036-6205)^{\star}$ : Responsible for the application of questionnaires, tabulation and wrote the results; EAP (0000-0001-6008-8671)*: Responsible for the application of questionnaires, tabulation and wrote the results; JRD (0000-0003-2805-2948)*: Collaborated with data analysis and discussion; PMMBF (0000-0001-7081-987X)*: drafted and reviewed the article, analyzed the data analysis and contributed to the intellectual concept of the study; MTM (0000-0002-3140-7562)*:analyzed the data analysis and contributed to the intellectual concept of the study and wrote the article. *ORCID (Open Researcher and Contributor ID).

\section{REFERENCES}

1. Cooper $C$, Mitchell $P$, Kanis JA. Breaking the fragility fracture cycle. Osteoporos Int. 2011;22(7):2049-50.

2. Who. Scientific Group on the assessment of osteoporosis at primary health care level. World Health Organization, Belgium, 2004.

3. Siris ES, Miller PD, Barrett-Connor E, Faulkner KG, Wehren LE, Abbott TA et al. Identification and fracture outcomes of undiagnosed low bone mineral density in postmenopausal women: results from the National Osteoporosis Risk Assessment. JAMA. 2001;286(22):2815-22.

4. Pinheiro MM, Ciconelli RM, Jacques NO, Genaro PS, Martini LA, Ferraz MB. The burden of osteoporosis in Brazil: regional data from fractures in adult men and women - The Brazilian Osteoporosis Study (BRAZOS). Rev Bras Reumatol. 2010;50(2):113-27.

5. Cosman F, de Beur SJ, LeBoff MS, Lewiecki EM, Tanner B, Randall S, et al. Clinician's Guide to Prevention and Treatment of Osteoporosis. Osteoporos Int. 2014;25(10):2359-81.

6. Sander B, Elliot-Gibson V, Beaton DE, Bogoch ER, Maetzel A. A coordinator program in post-fracture osteoporosis management improves outcomes and saves costs. J Bone Joint Surg Am. 2008;90(6):1197-205.

7. Pinheiro MM. Mortalidade após Fratura por Osteoporose. Arq Bras Endocrinol Metab. 2008;52(7):1071-2

8. Marinho BC, Guerra LP, Drummond JB, Silva BC, Soares MM. The burden of osteoporosis in Brazil. Arq Bras Endocrinol Metabol. 2014;58(5):434-43.

9. Giangregorio L, Papaioannou A, Cranney A, Zytaruk N, Adachi JD. Fragility fractures and the osteoporosis care gap: an international phenomenon. Semin Arthritis Rheum. 2006;35(5):293-305.

10. Compston J, Cooper A, Cooper C, Francis R, Kanis JA, Marsh D, et al. Guidelines for the diagnosis and management of osteoporosis in postmenopausal women and men from the age of 50 years in the UK. Maturitas. 2009;62(2):105-8.
11. Maeda SS, Borba VZ, Camargo MB, Silva DM, Borges JL, Bandeira F, et al. Recommendations of the Brazilian Society of Endocrinology and Metabology (SBEM) for the diagnosis and treatment of hypovitaminosis D. Arq Bras Endocrinol Metabol. 2014;58(5):411-33.

12. Ashe MC, Khan KM, Guy $P$, Janssen $P$, McKay HA. Fragility fracture and osteoporosis investigation. BCMJ. 2004;46(10):506-9.

13. Ward L, Tricco AC, Phuong P, Cranney A, Barrowman N, Gaboury I, et al. Bisphosphonate therapy for children and adolescents with secondary osteoporosis. Cochrane Database Syst Rev. 2007;17(4):CD005324.

14. Wells GA, Cranney A, Peterson J, Boucher M, Shea B, Robinson V, et al. Alendronate for the primary and secondary prevention of osteoporotic fractures in postmenopausal women. Cochrane Database Syst Ver. 2008;23(1):CD001155

15. Wells GA, Cranney A, Peterson J, Boucher M, Shea B, Robinson V, et al Etidronate for the primary and secondary prevention of osteoporotic fractures in postmenopausal women. Cochrane Database Syst Rev. 2008;23(1):CD003376.

16. Wells G, Cranney A, Peterson J, Boucher M, Shea B, Robinson V, et al. Risedronate for the primary and secondary prevention of osteoporotic fractures in postmenopausal women. Cochrane Database Syst Rev. 2008;23(1):CD004523.

17. Bandeira F, Paula FJA, Lazaretti-Castro M, Premaor MO. Targets in osteoporosis treatment. Arq Bras Endocrinol Metabol. 2014;58(5):409-10.

18. National Osteoporosis Foundation. Clinician's Guide to Prevention and Treatment of Osteoporosis. National Osteoporosis Foundation, Washington, 2010.

19. Li YT, Cai HF, Zhang ZL. Timing of the initiation of bisphosphonates after surgery for fracture healing: a systematic review and meta-analysis of randomized controlled trials. Osteoporos Int. 2015;26(2):431-41.

20. Szejnfeld VL, Jennings F, Castro CHM, Pinheiro MM, Lopes AC. Conhecimento dos Médicos Clínicos do Brasil sobre as Estratégias de Prevenção e Tratamento da Osteoporose. Rev Bras Reumatol. 2007;47(4):251-7. 